\title{
A modified WBANs MAC superframe using priority-criticality index table for managing pilgrims' emergency traffic in Hajj
}

\author{
Shah Murtaza Rashid Al Masud ${ }^{1}$, Asmidar Abu Bakar², Salman Yussof ${ }^{3}$ \\ ${ }^{1}$ College of Graduate Studies, Universiti Tenaga Nasional, Malaysia \\ ${ }^{2,3}$ College of Computer Science and Information Technology, Universiti Tenaga Nasional, Malaysia
}

\begin{tabular}{l}
\hline \hline Article Info \\
\hline Article history: \\
Received Jan 16, 2019 \\
Revised Feb 13, 2019 \\
Accepted Feb 27, 2019
\end{tabular}

\section{Keywords:}

Criticality index table

Emergency

Hajj pilgrims

Healthcare

MAC superframe

WBANs

\begin{abstract}
During Hajj, pilgrims suffer from various emergencies that should be managed in a real-time manner thus require deploying emerging technology. Based on our research it is found that the emergency medical circumstances among the pilgrims are due to the criticality level of certain physiological conditions those are by some means rely on five major types of the physiological data rate. Five major data types include heart rate, respiratory rate, body temperature, high or low blood pressure and blood sugar respectively which are obligatory to be transmitted real-time and ahead of other non-critical traffic as delay in its transmission may jeopardise human life. Hence, by the criticality constraints of pilgrims' physiological data, we primarily perform a traffic classification through literature review. By using classified critical traffic, we define the different priority levels to be used by WBANs hub or coordinator. Therefore, in this research, we apply an analytical method to develop the priority-criticality index table in such a way that there will be no queuing delay in the system. Since our research mainly focuses on to manage the emergency, therefore, for simplicity of critical data transmission, we modified the existing medium access control (MAC) superframe that obtains only one exclusive access period (EAP) slot. The modified MAC superframe structure is to perform efficiently even when more than one emergency traffic from different sensors aggregate to the WBANs coordinator for further transmission to the healthcare stations.
\end{abstract}

Copyright $\odot 2019$ Institute of Advanced Engineering and Science. All rights reserved.

\section{Corresponding Author:}

Shah Murtaza Rashid Al Masud,

College of Graduate Studies,

Universiti Tenaga Nasional,

Jalan Ikram-Uniten, 43000, Kajang, Selangor, Malaysia.

Email: smramasud@gmail.com

\section{INTRODUCTION}

Every year millions of pilgrims congregate at ritual sites of the holy place 'Kaaba' in Makkah for performing Hajj. The pilgrims during Hajj must stay and move around in a restricted environment which is mostly crowded. Pilgrims having various chronic and infectious diseases must be monitored continuously and in a real-time manner. In recent times, IEEE 802.1.5.6 based wireless body sensor networks (WBANs) are changing the various healthcare scenarios by providing heterogeneous medical data and signs to the healthcare stations as well as doctors and nurses thus improve real-time and distant healthcare services [1]. WBANs consist of various body sensors and a coordinator. The number of sensors used for the collection of information necessary for the monitoring and control of health conditions of the pilgrims depends on the pathologies and signs defined for each type of disease. For this reason, the type and number of sensors suppose to deploy may vary from one to another. These sensors sense data with different characteristics and requirements such as information about emergency health conditions of the pilgrims and to transmit to the healthcare stations. To transmit medical data through medium poses varieties of problems that must be 
satisfied with the quality of service requirements specially for the transmission of emergency traffics. The IEEE 802.15.6-2012 standard is natively designated for medical applications. To meet the requirements of this area, different levels of data priority and associated traffic have been introduced to ensure the proper management of traffic according to the importance of information as mentioned in Table 1 [1]. As presented in Table 1 the user priorities for accessing the medium are differentiated and classified into eight different access categories. Moreover, Table I depicts the contention window (CW) bounds for CSMA/CA of WBAN [1], where all the medical data belong to high and very high priority, and non-medical data belongs to average and low priority.

Table 1. Priorities Associated with Various Type of Traffic of WBANs

\begin{tabular}{|c|c|c|c|c|c|}
\hline \multirow{2}{*}{ Priority } & \multirow{2}{*}{$\begin{array}{l}\text { User } \\
\text { Priority } \\
\text { (UP) }\end{array}$} & \multirow{2}{*}{ Associated Traffic } & $\begin{array}{r}\text { Carrier-sense multip } \\
\text { avoidance }\end{array}$ & $\begin{array}{l}\text { access with collision } \\
\text { SMA/CA }\end{array}$ & \multirow{2}{*}{ Frame Type } \\
\hline & & & $\begin{array}{l}\text { Minimum contention } \\
\text { window (CWmin) }\end{array}$ & $\begin{array}{c}\text { Maximum contention } \\
\text { window }(\mathrm{CW} \max )\end{array}$ & \\
\hline \multirow{2}{*}{ Low } & 0 (Zero) & Background (BG) & 16 & 64 & \multirow{3}{*}{ Data } \\
\hline & 1 (One) & Best Effort (BE) & 16 & 32 & \\
\hline \multirow{3}{*}{ Average } & 2 (Two) & Excellent Effort (EE) & 8 & 32 & \\
\hline & 3 (Three) & Video $(\mathrm{VI})$ & 8 & 16 & \multirow[t]{2}{*}{ Data or management } \\
\hline & 4 (Four) & Voice (VO) & 4 & 16 & \\
\hline \multirow[b]{2}{*}{ High } & 5 (Five) & Medical data or control & 4 & 8 & \multirow[b]{2}{*}{ Data or management } \\
\hline & $6(\mathrm{Six})$ & $\begin{array}{l}\text { High priority medical } \\
\text { data or control }\end{array}$ & 2 & 8 & \\
\hline Very High & 7 (Seven) & $\begin{array}{c}\text { Emergency or medical } \\
\text { event report }\end{array}$ & 1 & 4 & Data \\
\hline
\end{tabular}

Based on the WBANs user priority (UP) level as presented in Table 1, the medical traffic or data packet is classified into three major classes which are emergency (EM) traffic, on-demand (OD) traffic, and normal (NR) traffic [1]. The emergency traffic obtains the highest level of user priority $\mathrm{UP}_{7}$, followed by the user priority for the on-demand traffic-UP $\mathrm{UP}_{6}$, and normal traffic with the lowest priority level-UP $\mathrm{U}_{5}$ Table 2 presents the definition and the mapping between different classes of WBANs traffic and its associated user priority.

Table 2. Classification of WBANs Medical Traffics

\begin{tabular}{cccc}
\hline $\begin{array}{c}\text { Level of User } \\
\text { priority }\end{array}$ & $\begin{array}{c}\text { Traffic or } \\
\text { Packet } \\
\text { Subtype }\end{array}$ & Full Name & Description \\
\hline 7 & EM & Emergency & $\begin{array}{c}\text { EM traffic consists of data values that exceed the normal threshold } \\
\text { value, and generally, they are the most critical aperiodic data packets } \\
\text { and delay sensitive. }\end{array}$ \\
6 & OD & $\begin{array}{c}\text { On-demand } \\
\text { Normal medical. } \\
\text { Periodic } \\
\text { checking }\end{array}$ & $\begin{array}{c}\text { OD traffic is designed for medical and nonmedical applications but } \\
\text { Thot delay sensitive. } \\
\text { correspond not to delay sensitive, periodic and regular measurement } \\
\text { of patient physiological parameters consists of average values. }\end{array}$ \\
\hline
\end{tabular}

It is to be noted that, traffic priorities may vary depending upon the values generated by the sensors that exceed the normal threshold value. Depending on the physiological event being monitored, the medical traffic could be either periodic or aperiodic, having either low or high priority. As mentioned earlier, emergency data frames are categorized as the highest user priority-UP $\mathrm{UP}_{7}$. But, the problem may occur when more than one emergency data from different sensors aggregate to the coordinator for further transmission to the healthcare stations. In a WBAN, the body coordinator or hub chooses and enables an access mode where exclusive access period (EAP) of IEEE802.15.6 MAC superframe is designed for transmission of emergency data. We assume that the beacon mode with the superframe scheme is selected by the hub. In this research, we develop priority-criticality index table on the basis of classified critical traffic. For simplicity of critical data transmission, we modified the existing medium access control (MAC) superframe that obtains only one exclusive access period (EAP) slot. The modified MAC superframe structure is to perform efficiently even when more than one emergency traffic from different sensors aggregate to the WBANs coordinator for further transmission to the healthcare stations. 


\section{RESEARCH METHOD}

\subsection{Classification of the Criticality Level of Emergency Traffic}

Several up to date literature have been reviewed to define and classify the criticality level of emeregcny traffic during Hajj. In general, traffics in WBANs are monitored in regular intervals because of sudden and random possibility of disease, illness, accident or other emergency issues and cases occur among the pilgrims during Hajj. As a result, the data rate may unexpectedly differ that affects data delivery system.

In IEEE 802.15.6, the entire time base is divided into superframe structures. For the transmission of single and concise length emergency data, the one-time slot is sometimes enough. But, the problem occurs when more than one emergency data from different sensors aggregate to the coordinator for further transmission to the healthcare stations. For urgent transmission of emergency data, in this research, we consider beacon-enabled superframe structure where the coordinator node sends beacon including information of superframe structure at the top of each superframe to synchronize each other. The design and development of the superframe structure based on IEEE 802.15.6 depend on the variation of severity or criticality of medical traffic and should investigate the effectiveness in meeting the low delay, energy efficiency requirements. Based on the criticality constraints of pilgrims' medical data packets, we primarily conduct the classification of traffic, and then different priority levels have been defined. The priority class as defined on the basis of traffic classification method is used by the coordinator while allocating slots for data packets.

Motivated by the challenges mentioned above, in our research, we focus on the transmission of emergency traffic based on the user priority level and priority-criticality index value as defined by the criticality level of pilgrims' medical data. In this model traffic with higher priority-criticality index will get quick and precise slot allocations then low priority-criticality index traffic without deteriorating each other. In our previous works [2]-[3] we have identified that during the pilgrimage, pilgrims suffer from different infectious and chronic diseases. Among the diseases, respiratory disease is the main health burden and the most common cause of admission to hospital followed by heat stroke, diabetes, cardiovascular disease, gastroenteritis, hypertension, skin disease and high fever. Hence, we prioritise the diseases suffering from pilgrims during Hajj according to the order of health burden and hospital admission as presented in Table 3. But, the criticality level of the diseases has been identified through further analysis of the causes of diseases and its severity level; and mortality rate.

Table 3. Name of Diseases and Order of Health Burden and Hospital Admission during Hajj

\begin{tabular}{lcc}
\hline \multicolumn{1}{c}{ Name of Diseases } & $\begin{array}{c}\text { Order of Health Burden } \\
\text { and Hospital Admission }\end{array}$ & Type of Diseases \\
\hline Respiratory diseases including & $1^{\text {st }}$ & Infectious \\
pneumonia, influenza, asthma, & $2^{\text {nd }}$ & Infectious \\
Heat stroke or heat attack & $3^{\text {rd }}$ & Chronic \\
Diabetes & $4^{\text {th }}$ & Chronic \\
Cardiovascular or Heart disease & $5^{\text {th }}$ & Infectious \\
Gastroenteritis & $6^{\text {th }}$ & Chronic \\
Hypertension & $7^{\text {th }}$ & Infectious \\
Skin disease and Dry eye & $8^{\text {th }}$ & Infectious \\
High Fever & & \\
\hline
\end{tabular}

During Hajj, the most common causes of death $43 \%$ are cardiovascular disease or heart disease. Respiratory disease is the most common cause of hospital admission during Hajj which is $57 \%$. Asthma, anxiety, pneumonia, congestive heart failure, lung disease, use of narcotics, or drug overdose is among other conditions that can change a normal respiratory rate. The main causes of heat stroke or heart attack are high body temperature (high fever) if more than $40{ }^{0} \mathrm{C}$ or $104{ }^{0} \mathrm{~F}$, rapid pulse (increasing of heart rate), and breathing problem. Since the pulse is caused by our heart beating, hence in our study we only consider the heart rate as one of the vital signs of disease identification.

It is found that hypertension is one of the reasons for pilgrims' discomfort during Hajj. Hypertension is the main and foremost reason for high blood pressure, heart attack, stroke, and kidney disease. Moreover, high blood pressure (BP) interrupts breathing, damaging heart, causes of diabetes and kidney infection; on the other hand, low blood pressure is the leading causes of stroke, heart attacks and kidney diseases. It is to be noted that some medical symptoms including body temperature, blood pressure, etc. usually are not considered as a vital sign of patients' criticality level but they are the major causes of criticality level or along with other symptoms they are often measured as the vital signs of patients' criticality level. Medical problems can easily be detected and measured from any location. Also, since, gastroenteritis, skin disease, 
dry eye can be quickly diagnosed and are less, therefore, in our research, we do not consider monitoring these diseases in pilgrims' during Hajj.

As mentioned earlier, deployment of WBANs and related technology are application specific, and we consider overcrowded ritual sites where pilgrims with various diseases need to be monitored and controlled by various sensor nodes. According to our study as mentioned earlier, it is found that heart rate, respiratory problem, body temperature, blood pressure, and blood sugar are the major causes of all the diseases and health problems [4]-[12]. The factors and parameters of different medical conditions and symptoms as found in [4][12] are co-related to the diseases and health-related problems among the pilgrims during Hajj as discussed previously in [2]-, 3]. To identify the acute and chronic diseases, medical signs and symptoms assembled in specific body sensors are used. The signs and symptoms are defined as an indication of the existence of a condition. According to our discussion, the criticality or severity level of disease or health problems encountered by the pilgrims during Hajj depend on various vital signs and related data rate which are classified and prioritized into the following types: 1) Heart rate (HR); 2) Respiratory rate (RR); 3) Body temperature (BT); 4) High or low blood pressure (BP); and 5) Blood sugar (BS) respectively.

Table 4 summarizes the disease characteristics considered in our research based on vital signs. We portray motivation and inspiration of classification and prioritization of vital signs of the diseases and identification of the threshold values of the vital signs from a differentiated traffic and scheduling scheme for WBANs [13], high and low threshold criticality based time slot allocation algorithms [14], and efficient channel access scheme for emergency traffic [15]. In Table 5, we summarize and classify the threshold values of vital signs and symptoms taking consideration the Table 4 and order of criticality into low threshold value (LTV), the normal threshold value (NTV), and the high threshold value (HTV). The threshold value is called as a critical threshold value when data value exceeds the normal threshold level.

Table 4. Vital Signs and Characteristics of Diseases

\begin{tabular}{|c|c|c|c|c|c|c|c|}
\hline \multirow[b]{2}{*}{ Vital Signs } & \multicolumn{7}{|c|}{ Diseases/ Health Problem } \\
\hline & Pneumonia & Asthma & $\begin{array}{l}\text { Heat } \\
\text { Stroke }\end{array}$ & Cardiovascular & Hypertension & $\begin{array}{l}\text { Kidney } \\
\text { disease }\end{array}$ & Diabetes \\
\hline Respiratory Rate (RR) & $\sqrt{ }$ & $\sqrt{ }$ & & & & & \\
\hline Heart Rate (HR) & & & $\sqrt{ }$ & $\sqrt{ }$ & $\sqrt{ }$ & & \\
\hline Blood Pressure (BP) & & & & $\sqrt{ }$ & $\sqrt{ }$ & & $\sqrt{ }$ \\
\hline Blood Sugar (BS) & & & & & & $\sqrt{ }$ & $\sqrt{ }$ \\
\hline Body Temperature (BT) & & & $\sqrt{ }$ & $\sqrt{ }$ & & $\sqrt{ }$ & \\
\hline
\end{tabular}

Table 5. Threshold Ranges of Vital Parameters

\begin{tabular}{ccccc}
\hline Vital Signs or Symptoms Parameter & $\begin{array}{c}\text { Periodic Normal } \\
\text { Values }\end{array}$ & $\begin{array}{c}\text { Low Threshold values } \\
\text { (LTV) }\end{array}$ & $\begin{array}{c}\text { High Threshold Values } \\
\text { (HTV) }\end{array}$ & Unit (s) \\
\hline Heart Rate (HR) & $60-100$ & $0-59$ & $101-180$ & $\mathrm{bpm}$ \\
Respiration Rate (RR) & $12-19$ & $0-11$ & $20-60$ & $>40$ \\
Body Temperature (BT) & 37 & N/A & $140-190$ & $\mathrm{C}$ \\
Blood Pressure Systolic (mmHg) & $90-120$ & $70-90$ & $90-100$ & $\mathrm{bpm}$ \\
Blood Pressure Diastolic (mmHg) & $60-80$ & $40-60$ & $>7.8$ & $\mathrm{bpm}$ \\
Diabetes/ blood sugar (random) & $4.4-7.8$ & $<4.4$ & $\mathrm{mmol} / \mathrm{L}$ \\
\hline
\end{tabular}

At WBANs hub level, when one emergency event occurs at any moment of time, then it is easy to tackle the situation, but to handle multiple such events in a timely manner requires more attention. Hence, to set the data priority to access the communication channel in MAC superframe, we divide the emergency data or traffic into five major types or classes based on the traffic severity or criticality level as found and discussed in Tables 4-5. Criticality denotes a level of medical emergency or health burden/ risk. We classified and prioritised WBANs data and emergency traffic on the basis of their QoS requirements for MAC which demand novel solution in WBANs. The criticality level of emergency traffic is presented as: 1) Extremely high critical traffic 2)Very high critical traffic, 3)High critical traffic, 4) Moderately critical traffic, and 5) Low critical traffic.

\subsection{Proposed Priority-Criticality Index Table for Emergency Traffic}

An analytical approach is used to define the priority-criticality index table for our research. WBANs body sensors are used to sense the vital signs or patients' physiological data. Moreover, in our research, a threshold value is considered as the parameter to identify the emergency level of physiological data or parameter. It is justified that, if the threshold value exceeded and is divided into low and high then it is regarded as emergency data and is considered as the life-critical data value for patients. Moreover, the low 
threshold value may approach to 0 and high threshold value approach to 1 or max value. In the following Table 6, the criticality level of a vital sign of diseases is given along with the name of sensors to be used to sense the data or vital sign of the patients, parameter name, and the threshold value of the diseases, signal frequency, data rate, and power consumption and accepted the delay.

Table 6. Criticality Level of Diseases Identification Using the Data Threshold Value

\begin{tabular}{|c|c|c|c|c|c|c|c|}
\hline $\begin{array}{l}\text { Vital sign of } \\
\text { disease } \\
\text { prioritised } \\
\text { based on } \\
\text { criticality level }\end{array}$ & $\begin{array}{l}\text { Name of } \\
\text { sensor }\end{array}$ & $\begin{array}{l}\text { Name of Diseases } \\
\text { (parameter signal) }\end{array}$ & $\begin{array}{l}\text { Threshold value (range } \\
\text { of Parameter) or range } \\
\text { of parameter }\end{array}$ & $\begin{array}{l}\text { Signal } \\
\text { Frequency }\end{array}$ & $\begin{array}{l}\text { Required } \\
\text { data rate } \\
(\mathrm{kbps})\end{array}$ & $\begin{array}{l}\text { Power } \\
\text { Consumption }\end{array}$ & $\begin{array}{l}\text { Latency/ } \\
\text { Accepted } \\
\text { Delay }\end{array}$ \\
\hline $\begin{array}{l}\text { Heart Rate } \\
\text { (Cardiovascular } \\
\text { diseases or } \\
\text { heart disease) }\end{array}$ & $\begin{array}{l}\text { ECG } \\
\text { Sensor }\end{array}$ & $\begin{array}{l}\text { ECG } \\
\text { (Electrocardiogra } \\
\mathrm{m} \text { is used for } \\
\text { early detection of } \\
\text { heart disease) }\end{array}$ & $\begin{array}{l}\text { Heartbeat in regular } \\
\text { sinus rhythm is } \\
\text { measured between the } \\
\text { range from } 60 \text { beats } \\
\text { per minute (bpm) to } \\
100 \text { bpm (specifically } \\
82 \mathrm{bpm} \text { ) } \\
\text { Amplitude range } 0.5-4 \\
\mathrm{mV}\end{array}$ & $\begin{array}{l}0.01-250 \\
\mathrm{~Hz}\end{array}$ & 6.0 & $\begin{array}{l}\text { Low to very } \\
\text { low }\end{array}$ & $\begin{array}{l}0.002 \mathrm{~s} \text { or } \\
2 \mathrm{~ms}\end{array}$ \\
\hline $\begin{array}{l}\text { Respiratory } \\
\text { Rate / breathing } \\
\text { problem }\end{array}$ & $\begin{array}{l}\text { Respirat } \\
\text { ory } \\
\text { sensor }\end{array}$ & Respiratory rate & $\begin{array}{l}12-20 \text { breaths } / \mathrm{min} \text { at } \\
\text { normal situation } \\
2-50 \text { breaths } / \mathrm{min}\end{array}$ & $0.1-10 \mathrm{~Hz}$ & 0.24 & $\begin{array}{l}\text { Low to very } \\
\text { low }\end{array}$ & $\begin{array}{l}0.05 \mathrm{~s} \text { or } \\
50 \mathrm{~ms}\end{array}$ \\
\hline $\begin{array}{l}\text { Body } \\
\text { temperature }\end{array}$ & $\begin{array}{l}\text { Body } \\
\text { Temper } \\
\text { ature } \\
\text { sensor }\end{array}$ & $\begin{array}{l}\text { A disease which } \\
\text { is influenced by } \\
\text { high body } \\
\text { temperature is } \\
\text { heat stroke, heart } \\
\text { attack during the } \\
\text { pilgrimage }\end{array}$ & $\begin{array}{l}\text { Body temperature }>= \\
40^{\circ} \mathrm{C} \text {, we consider as } \\
\text { high body temperature. } \\
\text { But, the range of } \\
\text { normal body } \\
\text { temperature has a } \\
\text { range from } 97^{\circ} \mathrm{F} \\
\left(36.1^{\circ} \mathrm{C}\right) \text { to } 99^{\circ} \mathrm{F} \\
\left(37.2^{\circ} \mathrm{C}\right) .\end{array}$ & $0-0.1 \mathrm{~Hz}$ & 0.0024 & $\begin{array}{l}\text { Low to very } \\
\text { low }\end{array}$ & $\begin{array}{l}0.25 \mathrm{~s} \text { or } \\
250 \mathrm{~ms}\end{array}$ \\
\hline $\begin{array}{l}\text { High or low } \\
\text { blood pressure } \\
\text { (BP) }\end{array}$ & $\begin{array}{l}\text { Blood } \\
\text { pressure } \\
\text { sensor }\end{array}$ & $\begin{array}{l}\text { Diseases which } \\
\text { are influenced by } \\
\text { low or high blood } \\
\text { pressure are } \\
\text { hypertension, } \\
\text { stroke, heart } \\
\text { disease, diabetes } \\
\text { and kidney } \\
\text { disease }\end{array}$ & $\begin{array}{l}\text { 90/60-120/80 mm Hg } \\
\text { (Systolic/ Diastolic) } \\
\text { (ideal and healthy) }\end{array}$ & $0-50 \mathrm{~Hz}$ & 1.2 & $\begin{array}{l}\text { Low to very } \\
\text { low }\end{array}$ & $\begin{array}{l}0.01 \mathrm{~s} \text { or } \\
10 \mathrm{~ms}\end{array}$ \\
\hline $\begin{array}{l}\text { Blood Sugar } \\
\text { (Diabetes) }\end{array}$ & $\begin{array}{l}\text { Glucose } \\
\text { Sensor }\end{array}$ & $\begin{array}{l}\text { Diabetes/ Glucose } \\
\text { level monitoring }\end{array}$ & $\begin{array}{l}4.4-7.8 \mathrm{mmol} / \mathrm{L}(79.2- \\
140.4 \mathrm{mg} / \mathrm{dl}) \\
\text { Random }\end{array}$ & N/A & 1 & $\begin{array}{l}\text { Low to very } \\
\text { low }\end{array}$ & $\begin{array}{l}0.025 \mathrm{~s} \\
\text { or } 25 \mathrm{~ms}\end{array}$ \\
\hline
\end{tabular}

Critical data are event-triggered traffic and is generated whenever a life-threatening situation occurs hence; it is to be delivered with minimum delay, and with no loss. On the other hand, normal physiological data of the pilgrims requires regular and scheduled monitoring but does not need strict delay or reliability constraints. In this research, we assume, emergency data comprise the highest priority; on-demand data encompass the second highest priority, and normal data contain the third highest priority, where, five sensors are to be used to sense the emergency data, usually, emergency data which are more likely to deviate from the threshold value. On the other hand, one sensor is to be used for collecting on-demand data to monitor the pilgrims' location. Pilgrims normal physiological or medical data which is within the range of threshold value will be collected periodically by the sensors deployed to collect the emergency data. It is to be further noticed that, threshold values are used to distinguish normal data from the critical data and through which the priority-criticality index is defined for our research. In combination with the highest user priority $\left(\mathrm{P}_{1}\right.$ : emergency data) and different levels of data or traffic criticality values $\left(\mathrm{C}_{1}-\mathrm{C}_{5}\right)$, a priority-criticality index is defined. The index is introduced to define the criticality level of emergency data as $I=P_{1} C_{i}$ where $i=1-5$ since in our research five nodes are assigned to sense five vital signs of pilgrims during Hajj.

Finally, priority-criticality index table ranges from $\left(\mathrm{P}_{1} \mathrm{C}_{1}-\mathrm{P}_{1} \mathrm{C}_{5}\right)$ having WBANs user priority 7. The higher the index value, the higher the criticality level of emergency data, hence the emergency traffic with the higher criticality level will allow transmitting with higher privilege. Also, on-demand or second highest or medium priority physiological data is determined by $\mathrm{P}_{2}$ having WBANs user priority 6 and the normal medical data or third highest or low priority medical data is defined by $\mathrm{P}_{3}$ having WBANs user 
priority 5. The body sensor nodes of WBANs are capable of sensing, processing and transmission of body signals. On the other hand, the body coordinator collects, sorts, processes and transmits the signals those have received from sensor nodes and sometimes from the healthcare centres (on-demand traffic).

In summary, critical data exceeds the normal threshold value and comprises low and high criticality threshold values. In our proposed mechanism all critical data values belong to emergency traffic which is aperiodic. The periodic data which includes normal threshold values are presented in Table 5 and Table 6. Based on the criticality level of pilgrims' diseases (which belong to the set of emergency data level) we set the different priority level for critical data and classify into five different categories as we present in Table 7. The channel access mechanism of all sorts of medical data will be discussed later in this paper.

Table 7. Proposed Criticality-Priority Index Table for Emergency Traffic

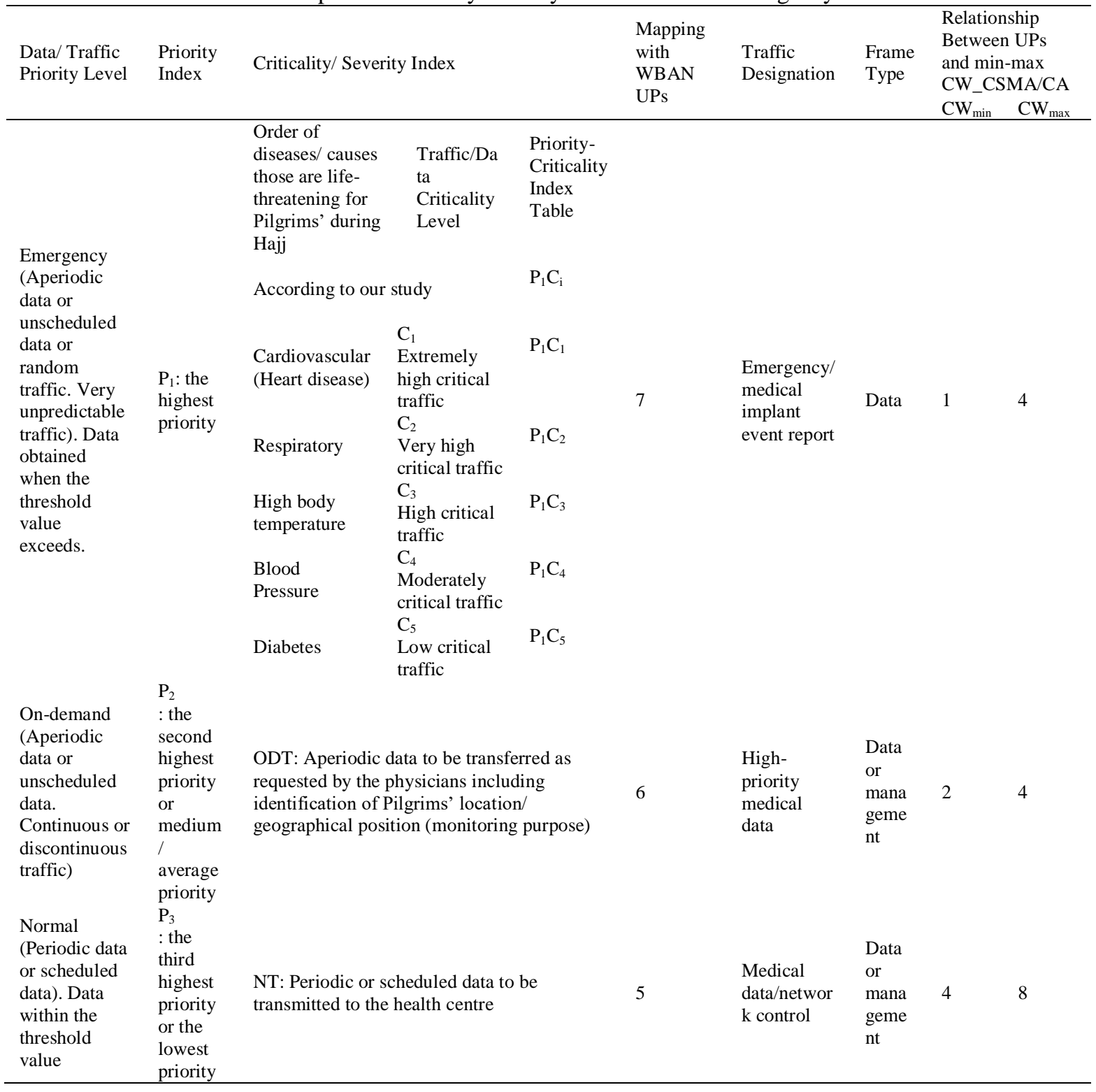

\section{RESULTS AND DISCUSSION}

\subsection{The Modified MAC Superframe Structure}

Some medium access control (MAC) protocols, primarily derived from the superframe structure of the MAC superframe of IEEE 802.15.4 is mainly based on the contention access period (CAP) which is a reason for data collisions and retransmissions in a network. In contention access period, traffics with higher priority dominant over low-priority which is in contrary the highest load traffic results in more delay and 
energy consumption. Hence, the design of a superframe with a fair and reasonable time slot allocation for all sorts of traffic can reduce delay and energy consumption under variable traffic loads [16]. IEEE 802.15.6 standard for WBANs coordinator specifies a medium access with three access modes for network management including 1. With beacon and with superframe, 2. Without a beacon and with superframe, and 3. Without a beacon and without superframe. Figure 1 shows the structure of a superframe in beacon mode as specified by IEEE 802.15.6 [1]. There are nine different access categories that indicate the user priorities for accessing the medium. At the beginning of each superframe, we find a beacon followed by two successive periods. Each period contains three sub-periods: EAP (Exclusive Access Phase), RAP (Random Access Phase) and Type I / II (also called MAP (Managed Access Phase)) consecutively. After these two periods, we have a frame $\mathrm{B} 2$, which proceeds the period contention access period (CAP).

The duration of the different periods in the superframe is variable, and their lengths are given according to the number of slots reserved. The structure of the superframe can be modified by deactivating definite periods [17].

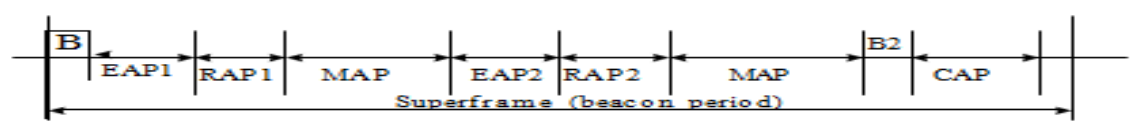

Figure 1. Beacon mode with superframe boundaries in IEEE 802.15.6

To transmit data frames at the highest UP (i.e., emergency or medical event report) a hub or sensor node may obtain contended allocations in EAP1 and EAP2. EAP1 and EAP2 periods are reserved for emergency medical traffic and RAP1, RAP2 and CAP are reserved for other normal medical or non-medical traffics. Table 8 shows the main characteristics of the different parts of IEEE 802.15.6 superframe. In the designing of MAC superframe structure, all signals are not to be treated with the same approach in the superframe. Moreover, superframe won't suit the condition when some medical emergency data or signals collide with some comparatively less life-critical signals and not promptly delivered in WBANs.

Table 8. Superframe Period as Defined by IEEE 802.15.6

\begin{tabular}{ccc}
\hline Period/ Slots & Type of Traffic \\
\hline Beacon & $\begin{array}{c}\text { A superframe is initialised by the beacon. Beacons occupy the first slot of each superframe. The main } \\
\text { functions of beacons are power management, clock synchronisation, identifying the coordinator etc. } \\
\text { Regular or ordinary traffic } \\
\text { Sanaged Access Phase- }\end{array}$ & $\begin{array}{c}\text { On-demand (Polling/Posting) traffic } \\
\text { MAP (MAP1 and MAP2) }\end{array}$ \\
$\begin{array}{c}\text { Exclusive Access Phase- } \\
\text { EAP (EAP1 and EAP2) }\end{array}$ & $\begin{array}{c}\text { Urgent or emergency traffic which is the highest } \\
\text { priority traffic, delay sensitive, so, failure of delivery } \\
\text { promptly may affect the life of the patient. }\end{array}$ \\
$\begin{array}{c}\text { Random Access Phase- } \\
\text { RAP (RAP1 and RAP2) }\end{array}$ & $\begin{array}{c}\text { Urgent or non-urgent random traffic is dedicated } \\
\text { both for regular and critical traffic. }\end{array}$ \\
Contention Access Phase- & I am dedicated to normal or regular traffic only. \\
CAP & Beacon two frame is proposed for indicating the beginning and the end of the CAP phase.
\end{tabular}

In this research, we consider superframe with beacon periods which is one of the three access modes of operation as stated in the adopted resolution of IEEE 802.15.6 standard. In a WBAN, the hub chooses and enables an access mode, and in our research we assume, the coordinator also selects the beacon mode with superframe. According to the adopted IEEE802.15.6 WBAN specifications, exclusive access period (EAP) carries out the transportation of emergency medical signals having the highest level of priority by categorising the traffic as user-priority $\mathrm{UP}_{7}$.

However, in emergency circumstances the number of simultaneously contending $\mathrm{UP}_{7}$ nodes (i.e., nodes with $\mathrm{UP}_{7}$ frames) may increase, results in high collision probability during EAP. Therefore, in our research, the priority of the emergency data has been set up using priority-criticality indices, and at the same time, the highest criticality level of emergency traffic/data shall get accessed to the channel or slot first during EAP period which is CSMA/CA based. Accordingly, based on the priority-criticality indices other emergency data frames or traffics shall occupy or access the channel using real-time traffic scheduling 
mechanism, and if the channel is already busy, then the subsequent traffic containing critical data frames are to be distributed in separate queues and access the channel next based on their level of criticality. As a result data collision and data retransmission can be avoided that result in low energy consumption, and low delay in transmission of life-saving emergency data. On the priority-based slot allocation in our research, the superframe allocates dedicated slots to all sorts of traffic classes from emergency to on-demand to normal traffic and slots are also assigned for different emergency traffic classes (according to data criticality level) to avoid data contention to access channel thus also result in low delay, low energy consumption and high throughput. In this proposed scheme, emergency traffic at $\mathrm{UP}_{7}$, on-demand traffic at $\mathrm{UP}_{6}$ and normal traffic at $\mathrm{UP}_{5}$. Since we focus on IEEE 802.15.6 synchronous mode (beacon mode with superframe), the proposed superframe structure is illustrated in Figure 2. In this scheme to analysis the channel reliably we assign EAP exclusively for emergency traffic by combining EAP1 and EAP2. EAP is defined exclusively for $\mathrm{UP}_{7}$ traffic. $_{\text {. }}$ Both EAP is aperiodic and contention-based phases. To better serve all critical data which belong to the emergency packet with the highest priority EAP1 is proposed. Random Access Period-RAP (combination of RAP1 and RAP2) is dedicated to on-demand traffic which is also a contention-based phase/period. A querybased or scheduled-based period Managed access period-MAP (combining MAP 1 and MAP 2) is set to support regular and non-critical or normal medical traffics. EAP phase is used for emergency critical traffics for not contending the access phases in the traffic.

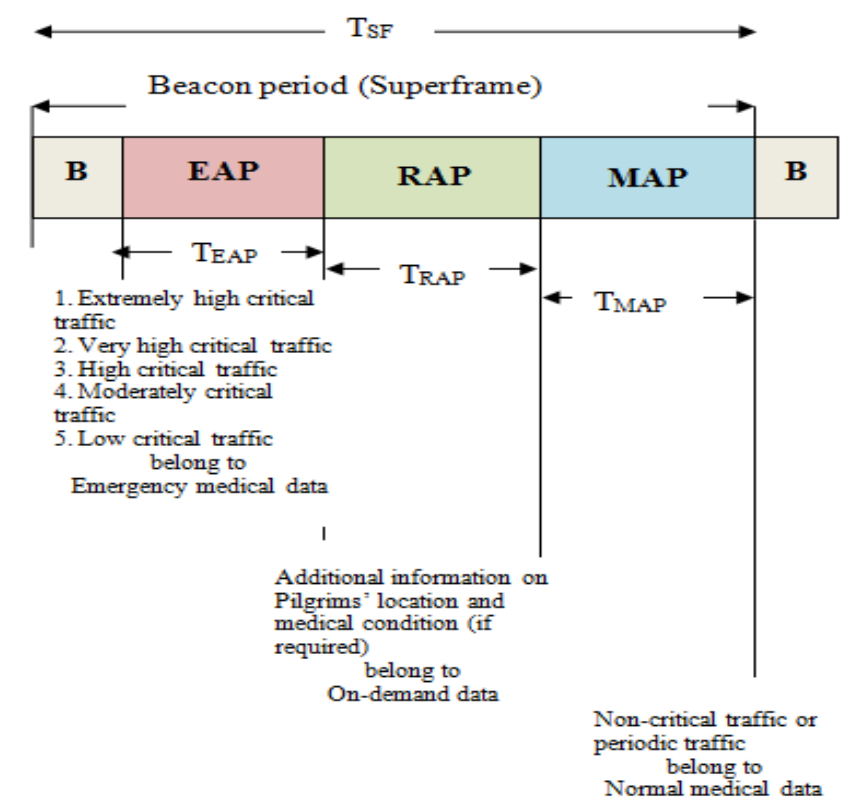

Figure 2. The proposed MAC superframe structure

As of Figure 2, the standard allows setting access phases other than EAP, RAP, and MAP to zero. The length of a superframe is denoted by $\mathrm{T}_{\mathrm{SF}}, \mathrm{T}_{\mathrm{EAP}}$ indicates the length of the EAP phase, $\mathrm{T}_{\mathrm{RAP}}$ represents RAP phase, and $\mathrm{T}_{\text {MAP }}$ stands for MAP period. The access phases used for the transport of various traffic classes and related UPs are listed in Table 9 which is based on the Table 7 and Table 8 as presented earlier. In this proposed superframe structure of the MAC protocol, the contention access phase (CAP) has not been considered at all for the simplicity of the scheme.

Table 9. Allocation of Access Phases for the Proposed Superframe

\begin{tabular}{|c|c|c|c|c|}
\hline $\begin{array}{l}\text { User priority (UP) and } \\
\text { traffic level as of } \\
\text { IEEE802.15.6 }\end{array}$ & Priority Index & $\begin{array}{l}\text { Criticality/ Severity } \\
\text { Index }\end{array}$ & $\begin{array}{l}\text { Priority-Criticality } \\
\text { Index Table }\end{array}$ & $\begin{array}{l}\text { Access Phase and } \\
\text { Type }\end{array}$ \\
\hline $\mathrm{UP}_{7}$ & $\mathrm{P}_{1}$ & $\mathrm{C}_{\mathrm{i}}=\{1,2,3,4,5\}$ & $\begin{array}{l}\mathrm{P}_{1} \mathrm{C}_{\mathrm{i}}=\left\{\mathrm{P}_{1} \mathrm{C}_{1}, \mathrm{P}_{1} \mathrm{C}_{2}, \mathrm{P}_{1} \mathrm{C}_{3}\right. \\
\left.\mathrm{P}_{1} \mathrm{C}_{4} \mathrm{P}_{1} \mathrm{C}_{5}\right\}\end{array}$ & EAP \\
\hline $\begin{array}{l}\mathrm{UP}_{6} \\
\mathrm{UP}_{5}\end{array}$ & $\begin{array}{l}\mathrm{P}_{2} \\
\mathrm{P}_{3}\end{array}$ & $\begin{array}{l}\mathrm{P}_{1} \mathrm{C}_{\mathrm{i}}=0 \\
\mathrm{P}_{1} \mathrm{C}_{\mathrm{i}}=0\end{array}$ & & $\begin{array}{l}\text { RAP } \\
\text { MAP }\end{array}$ \\
\hline
\end{tabular}




\section{CONCLUSION}

Every year millions of pilgrims congregate at ritual sites of the holy place 'Kaaba' in Makkah for performing Hajj. Providing the best healthcare services and facilities among the pilgrims those who are suffering from various emergency conditions, e.g. chronic diseases and sudden illness, trauma and accidents at the full environment is a challenging issue. In recent times, IEEE 802.1.5.6 based wireless body sensor networks (WBANs) are changing the various healthcare scenarios by providing heterogeneous medical data and signs to the healthcare stations as well as doctors and nurses thus improve real-time and distant healthcare services. One of the essential requirements of WBANs is to control the channel access in the network accurately. In IEEE 802.15.6, the entire time base is divided into superframe structures of medium access control (MAC) protocol. According to our study, physiological and biological parameters of the human body can be changed in general when human behaviour and surrounding environment changes can lead to a different medical situation as an emergency, on-demand and normal. However, life-critical data exceeds the normal threshold value and consists of low and high criticality threshold values and standards. Based on our research, the reasons behind critical medical situations during Hajj are classified into five major types of data rate, e.g. heart rate, respiratory rate, body temperature, high or low blood pressure and blood sugar respectively. The criticality level of medical data is also defined according to the findings above, and it is to be noted that, all critical data values belong to emergency traffic which is aperiodic. Critical or emergency data is obligatory to be transmitted ahead of other non-critical traffic as delay in its transmission may jeopardise human life. Therefore, in our research we define a different set of medical issues encounter by the pilgrims, related vital signs and symptoms, various data rate and threshold values. We prioritised the criticality level of the emergency issue into five different types and set up a priority-criticality index table as presented in the specific chapters with tables and diagrams. Finally, for the real-time and delay efficient data transmission a modified superframe of MAC for WBAN has also been proposed. For the simplicity of the superframe, four related slots are recommended including the beacon mode where EAP phase is dedicated for transmission of the critical emergency traffic in the network. In our future work, we will analytically study the proposed model that should satisfy low delay and energy efficiency issues as well.

\section{REFERENCES}

[1] Standard for Local and metropolitan area networks Part 15.6: Wireless Body Area Networks," IEEE Standard 802.15.6-2012, vol., no., pp.1-271, Feb. 292012

[2] Shah Murtaza Rashid Al Masud, Asmidar Abu Bakar, Salman Yussof, 'Determining the Types of Diseases and Emergency Issues in Pilgrims During Haji: A Literature Review' International Journal of Advanced Computer Science and Applications(IJACSA), 7(10), 2016

[3] Shah Murtaza Rashid Al Masud, Asmidar Abu Bakar, Salman Yussof, 'A Systematic Review of Technological Issues In Monitoring Pilgrims' Health During Hajj: Current State, Challenges And Future Directions', JATIT, 96(7), 2018

[4] ECG: https://meds.queensu.ca/central/assets/modules/ECG/normal_ecg.html, last accessed in November 2018

[5] ECG: https://meds.queensu.ca/central/assets/modules/ECG/normal_values.html, last accessed in November 2018

[6] Vital Sign: https://my.clevelandclinic.org/health/articles/10881-vital-signs, last accessed in November 2018

[7] Respiratory and Heart Rate: https://www.sleeprenewal.co.za/heart-and-breathing-rate, last accessed in November 2018

[8] Body Temperature and Medical vital data: https://medlineplus.gov/ency/article/001982.htm, last accessed in November 2018

[9] Medical vital data: https://www.urmc.rochester.edu/encyclopedia/content.aspx?ContentTypeID=85\&ContentID=P00866, last accessed in November 2018

[10] Blood Pressure: http://www.bloodpressureuk.org/BloodPressureandyou/Thebasics/Blood pressure chart, last accessed in November 2018

[11] Blood Pressure: https://www.cdc.gov/bloodpressure/measure.htm, last accessed in November 2018

[12] Diabetes and Blood Sugar: https://www.diabetes.co.uk/diabetes_care/blood-sugar-level-ranges.html, last accessed in November 2018

[13] Kateretse, Cecile, Ga-Won Lee, and Eui-Nam Huh. "A practical traffic scheduling scheme for differentiated services of healthcare systems on wireless sensor networks." Wireless personal communications 71.2 (2013): 909-927.

[14] Ambigavathi, M., and D. Sridharan. "Traffic Priority Based Channel Assignment Technique for Critical Data Transmission in Wireless Body Area Network." Journal of medical systems 42.11 (2018): 206.

[15] K. S. Deepak and A. V. Babu, "Improving Reliability of Emergency Data Frame Transmission in IEEE 802.15.6 Wireless Body Area Networks," IEEE Systems J., vol. PP, no. 99, pp. 1-12, 2017

[16] Henna S, Sajeel M, Bashir F, Asfand-E-Yar M, Tauqir M. A Fair Contention Access Scheme for Low-Priority Traffic in Wireless Body Area Networks. Sensors (Basel). 2017; 17(9):1931. Published 2017 Aug 23. doi:10.3390/s17091931

[17] K. A. Ali, J. H. Sarker, and H. T. Mouftah, "Urgency-based MAC protocol for wireless sensor body area networks," in Proc. IEEE Int. Conf. Commun. Workshops, Cape Town, South Africa, May 2010 